\title{
Regulation of VLDL synthesis and secretion in the liver
}

\author{
D Gruffat, D Durand, B Graulet, D Bauchart
Laboratoire croissance et métabolismes des herbivores, unité de recherches métabolismes énergétique et lipidique, Centre de recherches Clermont-Ferrand-Theix, Inra, \\ 63122 Saint-Genès-Champanelle, France
}

(Received 15 January 1996; accepted 6 May 1996)

\begin{abstract}
Summary - The production of very low density lipoproteins (VLDL) by the liver results from very complex processes that involve coordinated mechanisms of both protein and lipid synthesis and packaging. Alterations in these metabolic functions can cause negative effects on the health of human subjects or animals. The objectives of this paper were to review the latest developments in the biological mechanisms of these processes and the role of nutritional and hormonal factors. The present study addresses the following issues: i) the main steps in the hepatic metabolism of lipids (long-chain fatty acids, triacylglycerols, phospholipids) and proteins (apolipoprotein B, microsomal transfer protein) primarily involved in the synthesis and secretion of VLDL particles; ii) the metabolic deviations of hepatic VLDL (hypo- and overproduction) in man, rodents and farm animals (poultry, dairy cows).
\end{abstract}

\section{liver / triacylglycerol / VLDL secretion / regulating factors / steatosis}

Résumé - Régulation de la synthèse et de la sécrétion des VLDL par le foie. La formation par le foie de particules de lipoprotéines de très basse densité de type VLDL implique un processus très complexe qui nécessite la synthèse et l'assemblage coordonnés des constituants protéiques et lipidiques. Le dysfonctionnement de cette fonction hépatique peut provoquer des effets néfastes sur la santé des sujets. Le but de cette revue est de présenter les données les plus récentes et les concepts actuels concernant les mécanismes mis en jeu dans ces processus, ainsi que le rôle des facteurs de régulation de type nutritionnel et hormonal. Les points majeurs abordés dans cette synthèse concer-

\footnotetext{
Abbreviations: apoB: apolipoprotein B; CE: cholesteryl esters; DAG: diacylglycerols; DGAT: diacylglycerol acyltransferase; ER: endoplasmic reticulum; FABP: fatty acid binding protein; FA: fatty acids; GPAT: glycerol-3 phosphate acyltransferase; IDL: intermediate density lipoproteins; LDL: low density lipoproteins; LCFA: long-chain fatty acids; LPA: lysophosphatidic acid; LPAT: Iysophosphatidic acid acyltransferase; MTP: microsomal transfer protein; NEFA: nonesterified fatty acids; PA: phosphatidic acid; PAP: phosphatidic acid phosphatase; PC: phosphatidyl choline; PDI: protein disulphide isomerase; PL: phospholipids; PUFA: polyunsaturated fatty acids; RER: rough endoplasmic reticulum; TAG: triacylglycerols; VLDL: very low density lipoproteins.
} 
nent, d'une part, les particularités des principales étapes du métabolisme hépatique des lipides (acides gras, triglycérides, phospholipides) et des protéines (apolipoprotéine $B$, protéine microsomale de transfert des triglycérides) majoritairement impliquées dans la synthèse et la sécrétion des VLDL. La deuxième partie de cette revue décrit les mécanismes et les facteurs nutritionnels et hormonaux impliqués dans les déviations du métabolisme hépatique des VLDL (hypersécrétion, hyposécrétion) chez l'homme et les rongeurs de laboratoire et chez les animaux d'intérêt zootechnique (volaille, vache laitière).

foie / triglycérides / sécrétion de VLDL / facteurs de régulation / stéatose

\section{INTRODUCTION}

The production of very low density lipoproteins (VLDL) rich in apolipoprotein $B$ (apoB) and triacylglycerols (TAG) by the liver involves complex processes such as synthesis and the coordinated assembly of protein components (apolipoproteins) and of hydrophilic (phospholipids, free cholesterol) and hydrophobic (TAG, cholesteryl esters) lipid components (fig 1). This hepatic function enables mammals to transport efficiently a powerful source of energy either for storage in adipose tissues or for utilization, predominantly by muscle tissues. However, disorders in the liver lipotrope function may lead to diseases (overproduction of VLDL and coronary artery diseases, defect in VLDL

Hepatic compartment

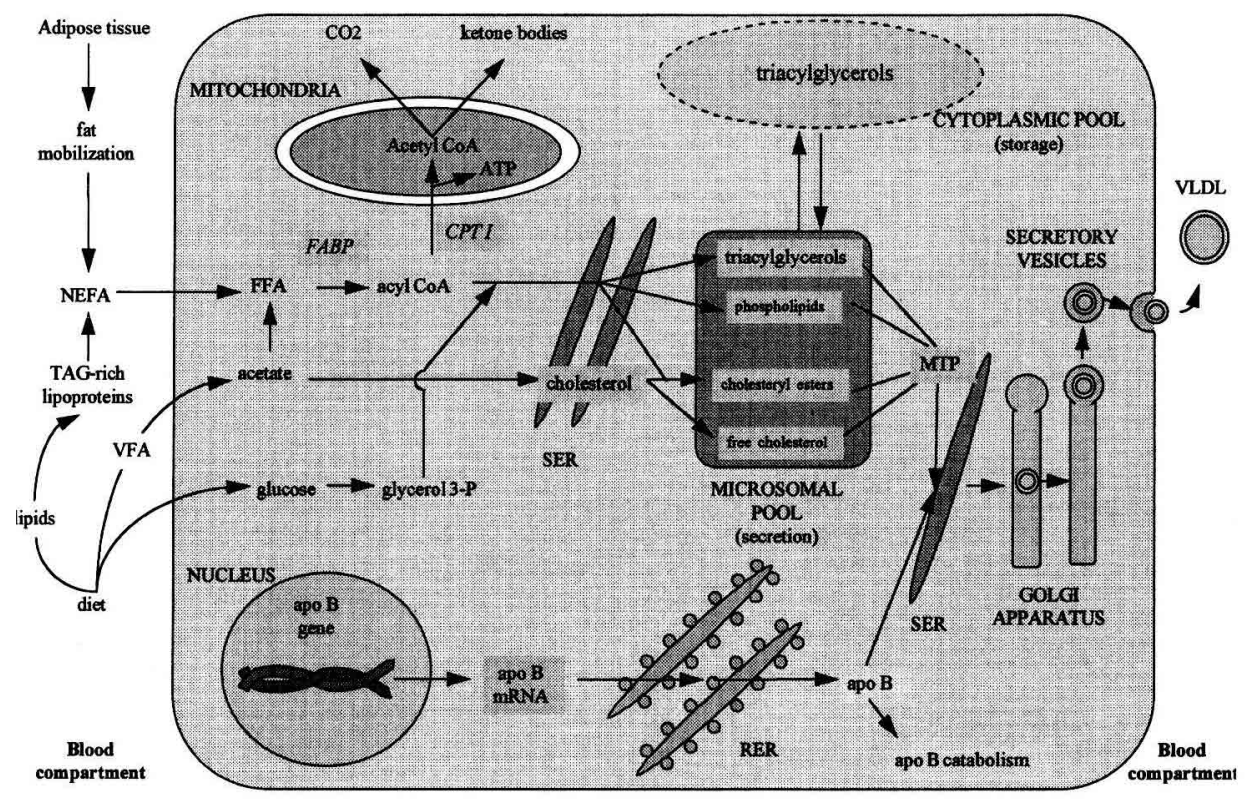

Fig 1. Schematic representation of the different processes involved in the synthesis and secretion of very low density lipoproteins (VLDL) in animal livers. apo B: apolipoprotein B; CPT I: carnitine palmitoyltransferase I; FABP: fatty acid binding protein; FFA: free fatty acids; MTP: microsomal transfer protein; NEFA: nonesterified fatty acids; RER: rough endoplasmic reticulum; SER: smooth endoplasmic reticulum; VFA: volatile fatty acids. 
production and liver steatosis-cetoacidosis). Several reviews have described the different steps of synthesis, assembly and secretion of VLDL in the liver and the regulating factors involved (Gibbons, 1990; Vance and Vance, 1990; Glickman and Sabesin, 1994). The present paper details the recent developments and understandings of the mechanisms involved in the hepatic synthesis of VLDL and how these are affected by different nutritional and hormonal factors.

\section{VLDL SYNTHESIS AND SECRETION IN THE LIVER}

\section{Fatty acid metabolism}

Long-chain fatty acids (LCFA) entering the liver are derived from plasma nonesterified fatty acids (NEFA) mobilized from adipose tissues during fasting conditions or from hydrolysis of dietary TAG during the postprandial period. The hepatic uptake of NEFA is driven by mass action and therefore depends on their concentration and the rate of blood flow into the liver (Pethick et al, 1984). In the liver, LCFA can also be synthesized from acetyl-CoA produced by the catabolism of excess glucose. The metabolic fates of LCFA in hepatocytes are i) the esterification into TAG and, to a lesser extent, into phospholipids (PL) and cholesteryl esters (CE); ii) the complete oxidation to $\mathrm{CO}_{2}$ generating ATP molecules or the incomplete oxidation to acetate and ketone bodies (fig 1) (Zammit, 1990). The metabolism of LCFA in the liver depends on the feeding conditions. In the fed period, carbohydrate ingestion favors esterification of LCFA by increasing availability of glycerol-3 phosphate produced from glucose and by inhibiting LCFA oxidation by maintaining high levels of malonyl-CoA, an inhibitor of carnitine transferase (McGarry and Foster, 1980). In the same way, increasing the supply of dietary LCFA to the liver stimulates esterifi- cation of LCFA to TAG but affects their secretion as VLDL (Francone et al, 1992). In the fasting period, the hepatic level of malonylCoA decreases which eliminates LCFA oxidation inhibition (McGarry et al, 1978). Such a situation favors acetyl-CoA formation and its subsequent oxidation. The length and the degree of unsaturation of the exogenous fatty acid (FA) carbon chain entering the liver may also control the intrahepatic metabolism of these FA. Medium-chain FA raise hepatic TAG synthesis levels in rats (Geelen et al, 1995) whereas $n-3$ polyunsaturated $F A$ (PUFA) are preferentially oxidized to ketone bodies (Rustan et al, 1992). FA metabolism in the liver is also under hormonal control. Insulin inhibits the oxidation of FA but stimulates the formation of LCFA from glucose and the synthesis of TAG from LCFA (Zammit, 1995).

\section{Triacylglycerol metabolism}

The hepatic synthesis of TAG generally proceeds along a sequence involving four reactions: three esterification reactions and one hydrolysis reaction. The first reaction is the acylation of glycerol-3 phosphate to acylglycerol-3 phosphate (ie, lysophosphatidic acid, LPA) which occurs on the endoplasmic reticulum (ER) or in the mitochondria by glycerol-3 phosphate acyltransferase (GPAT). In rat liver, the mitochondrial form of this enzyme (GAT, EC 2.3.1.15) has a specificity for saturated acyl-CoA whereas the microsomal form (GPAT, EC 2.3.1.15) apparently exhibits no FA specificity (Vancura and Haldar, 1994). It is not clear, however, whether the acyltransferase activity is due to a single enzyme with a dual specificity or to two enzymes with different specificities. Mitochondrial LPA is carried by the liver fatty acid binding protein (FABP) to the ER (Vancura and Haldar, 1992) where a second acylation, catalyzed by the lysophosphatidic acid acyltransferase (LPAT, EC 
2.3.1.51) produces phosphatidic acid (PA). The third step of TAG synthesis consists of hydrolysis of the phosphate ester bond of $P A$, yielding diacylglycerols (DAG), by the phosphatidic acid phosphatase (PAP, EC 3.1.3.4) located in the cytosol and in the microsomes of hepatocytes. These three first reactions are the same as those of PL synthesis which mainly occurs in the ER. The fourth and last reaction is specific to TAG synthesis. It consists of the acylation of DAG to TAG by microsomal diacylglycerol acyltransferase (DGAT, EC 2.3.1.20). During the last 5 years, numerous studies have been carried out to specify the relative importance and the mechanisms by which dietary FA control TAG synthesis in hepatocytes. Recent investigations on rat hepatocytes have emphasized GPAT activity as the main limiting step controlling the overall flux of LCFA through the esterification pathway to PL or TAG (Stals et al, 1994), irrespective of the dietary LCFA composition (Rule, 1994). Dietary lipids, rich in n-3 PUFA (from fish oil), led to a decrease in GPAT activity that was positively correlated with the induction of hypotriglyceridemia (Willumsen et al, 1993). In fact, this decrease in TAG synthesis originated from the greater oxidation of n-3 PUFA, therefore reducing their availaibility for esterification (Willumsen et al, 1993). Data on the regulation of PAP and DGAT activities by dietary lipid sources are still conflicting. Several recent studies on rat liver revealed that diets containing fish or safflower oil reduced PAP activity more efficiently than diets containing palm or sunflower oil, without altering the DGAT activity (AL-Shurbaji et al, 1991; Halminski et al, 1991). More recently, Rustan et al (1992) demonstrated that the source of dietary PUFA (fish oil vs sunflower oil or linseed oil) has no effect on PAP activity whereas Willumsen et al (1993) indicated that eicosapentaenoic acid (EPA, C20:5n-3) from fish oil stimulated DGAT activity. Moreover, in rats fed fish oil, hepatic DGAT activity was significantly reduced when com- pared with rats fed corn oil (Geelen et al, 1995). DGAT activity does seem to be modulated by the length of the FA carbon chain since diets containing medium-chain FA (mainly constituted of $\mathrm{C} 8: 0$ and $\mathrm{C} 10: 0$ ) could stimulate this activity more efficiently than diets containing corn oil (Geelen et al, 1995).

LCFA synthesized de novo in hepatocytes, lipoprotein remnants returning to the liver and plasma NEFA taken up by the liver are the potential sources of LCFA for the hepatic synthesis of TAG. It has been shown that hepatic de novo synthesis of LCFA provides only a small fraction of the newly secreted VLDL both in rats (Gibbons, 1990) and man (Hellerstein et al, 1991). On the other hand, many in vitro studies have clearly shown that extracellular LCFA (mainly NEFA) are capable of providing the bulk of nascent VLDL-TAG (Gibbons, 1990; Gibbons et al, 1992). Time-course studies carried out on rat hepatocytes in culture (Gibbons et al, 1992) and in vivo in the sheep liver (Pullen et al, 1988), however, suggest that the TAG synthesized from plasma NEFA are not immediately incorporated into the nascent VLDL particles, but are initially transferred into a temporary storage pool, probably located in the hepatocyte cytosol (fig 1). The precise pathways through which TAG are recruited from this pool to meet the requirement for VLDL assembly and secretion are still unknown. However, cytosolic TAG are not likely to be transferred as intact molecules into nascent VLDL particles but undergo lipolysis followed by re-esterification of the resulting LCFA in microsomes (Mooney and Lane, 1981; Wiggins and Gibbons, 1992). The chemical structure of the lipolytic factors involved in the TAG cycle, their catalytic properties and their precise location within the cell, are unknown. Data from different studies have only demonstrated that these lipolytic processes do not involve the activities of either lysosomal acid lipase, hormone-sensitive lipase or exogenous lipopro- 
tein lipase absorbed onto hepatic sinusoids (Wiggins and Gibbons, 1992).

\section{Phospholipid metabolism}

Phosphatidyl choline (PC), the major phospholipid component of VLDL, is located exclusively on the hydrophilic surface of the particles. Inhibition of PC biosynthesis by choline deprivation in rat hepatocytes strongly reduces VLDL secretion (Yao and Vance, 1988). The requirements for active PC synthesis were shown to be highly specific since the addition of ethanolamine or monomethylethanolamine (which is converted into phosphatidyl monomethylethanolamine) into the culture medium of rat hepatocytes did not restore VLDL secretion (Yao and Vance, 1989). The biosynthetic origin of $P C$ is not an important factor since conventional VLDL secretion by cultured hepatocytes can be restored by the addition of choline, methionine (which promotes PC biosynthesis via the methylation of phosphatidyl ethanolamine) or lyso-PC (which can be acylated to PC) (Robinson et al, 1989). The mechanism by which choline deprivation causes a reduction in the secretion of VLDL was investigated by Verkade et al (1993). These authors showed that the number of VLDL particles assembled in the ER was similar in choline-deficient and choline-supplemented rats, but that the Golgi fraction was lower in the choline-deficient animals only. These data suggest a possible protection mechanism for the neosynthesized apoB from intracellular degradation by choline during the migration of apoB from the ER to the Golgi apparatus (Verkade et al, 1993).

\section{ApoB synthesis}

Human apoB is a large, hydrophobic protein of 4536 amino acids with a molecular mass of approximatively $520 \mathrm{kDa}$. This protein, termed apoB-100, is synthesized exclusively in the liver. ApoB-100 contains both hydrophobic lipid-binding regions, which participate in the assembly of nascent lipoproteins, and hydrophilic sequences which interact with the polar aqueous environment. ApoB-100 also contains an LDLreceptor binding domain that is involved in the uptake of plasma IDL and LDL (and possibly VLDL) by tissues (Young, 1990). Numerous studies support the concept that hepatic apoB-100 secretion is metabolically regulated. Various metabolic states such as food deprivation and carbohydrate overload alter the level of hepatic apoB secretion, although the amount of apoB-100 mRNA is generally constant in hepatocytes. In vitro studies showed that free FA (butyrate, oleate) or insulin (Dashti et al, 1989; Pullinger et al, 1989; Kaptein et al, 1991) also modulate apoB secretion without any modification of the apoB-100 mRNA level. These results indicate that, in most physiological or nutritional situations, apoB-100 mRNA, which has a relatively long half-life of $16 \mathrm{~h}$ (Pullinger et al, 1989), does not respond to acute stimuli. These observations have focused attention on the co- and posttranscriptional mechanisms that could modulate apoB-100 production (Adeli et al, 1995). In HepG2 cell and rat hepatocyte cultures, insulin and thyroid hormone modify the rate of apoB mRNA translation (Theriault et al, 1992a, b). Recent data clearly demonstrated a rapid degradation of newly synthesized apoB-100 (>50\%) in rat hepatocytes (Sparks and Sparks, 1990) and HepG2 cells (Sato et al, 1990). This process may regulate the number of molecules of apoB-100 that enter the secretory pathway (Borchardt and Davies, 1987). Despite numerous data that demonstrated the hepatic degradation of newly synthesized apoB, little is known about this degradative pathway and its regulation. Recently, Cartwright and Higgins (1995b) identified at least two intracellular sites of apoB degradation, the 
ER and Golgi compartment, involving the activities of several proteases. In the in vitro degradation systems (permeabilized HepG2 cells), apoB catabolism was $\mathrm{pH}$ dependent and was stimulated by conditions of high temperature and by ATP. This proteolytic activity did not require calcium but was strongly influenced by the cysteine protease inhibitor (Adeli, 1994). The rate of apoB catabolism is stimulated by insulin (Sparks and Sparks, 1990) and decreased by oleate (Dixon et al, 1991; Furukawa et al, 1992). The number of newly synthesized apoB molecules available for secretion is modulated by the amount of TAG (Wu et al, 1994), CE (Cianflone et al, 1990; Dashti, 1992) and PL (Vance and Vance, 1990; Verkade et al, 1993) in the microsomes. The addition of oleate to the HepG2 or McArdle-RH777 cell medium highly stimulates apoB secretion (White et al, 1992; Sakata et al, 1993), which is correlated with an increase in the intracellular TAG level. The authors concluded that TAG would protect apoB through the formation of an apoBTAG complex that is resistant to proteolysis (Furukawa et al, 1992; Sakata et al, 1993). Conversely, inhibition of TAG synthesis by triacsin $D$ prevents this oleate effect and favors intrahepatic apoB degradation (Wu et al, 1994).

\section{Microsomal transfer protein}

The microsomal transfer protein (MTP) catalyzes the transport of TAG, CE and PL from the ER membranes to the site of VLDL assembly. Exclusively found in the lumen of microsomes isolated from the liver and intestine, this protein is a soluble heterodimer which consists of two subunits of 58 and $97 \mathrm{kDa}$, respectively (Gordon et al, 1995). The smaller subunit corresponds to a multifunctional enzyme, the protein disulphide isomerase (PDI), which plays several roles in protein folding within the lumen of the ER. The precise role of PDI in the functioning of MTP is still unclear. The two subunits, however, form a tight, nonexchanging complex, and the dissociation of this complex leads to a loss in TAG transfer activity (Wetterau et al, 1991). The cDNA encoding the larger subunit of MTP has been cloned and sequenced from the livers of cows, humans (Sharp et al, 1993) and hamsters (Lin et al, 1994). The deduced amino acid sequence of the bovine and hamster MTP is $86 \%$ identical to that in humans, indicating high conservation of MTP between species. MTP has a specific preference for binding and transporting hydrophobic lipids (TAG, CE) over PL. Indeed, its lipid transport rates decrease as follow: TAG > DAG > free cholesterol > PC. Within a lipid class, MTP tends to transport molecules with lower polarity more easily (Jamil et al, 1995). The mechanisms of lipid transport by MTP between membranes have been studied in kinetic and lipid-binding experiments. It has been suggested that MTP shuttles lipids to the newly synthesized apoB in the lumen of the ER (Atzel and Wetterau, 1994). The expression of the gene encoding the large subunit of MTP is regulated by nutritional factors that alter the levels of in vivo VLDL synthesis by the liver (Lin et al, 1994). Thus, high-fat and highsucrose diets given to hamsters for 1 month increased the hepatic large subunit mRNA level by $55 \%$ whereas a prolonged fast for $48 \mathrm{~h}$ had no effect (Lin et al, 1994). In the hamster, the hepatic level of MTP MRNA increased with high-fat rations and with high levels of saturated FA $(\mathrm{C} 14, \mathrm{C16})$ as compared with unsaturated FA (C18:1n-9, C18:2n-6) in the diet (Bennett et al, 1995). The mRNA level for the MTP larger subunit in HepG2 cells decreased by up to $80 \%$ in response to increasing insulin concentrations (Lin et al, 1995). However, there was no acute effect of insulin on MTP activity in HepG2 cells owing to the long half-life of the MTP protein in the hepatocytes (4.5 days) (Lin et al, 1995). 


\section{VLDL assembly}

Although there is still considerable controversy over the details of the VLDL assembly sequential process, it is commonly accepted that hepatic VLDL assembly is broken down into two steps (Gordon et al, 1995). The first step consists of the translocation of apoB into the lumen of the RER (where apoB is folded) and subsequently into the initial lipid supply to form nascent, small and dense lipoprotein particles. The second step consists of the maturation of the particles through the incorporation of neutral lipids into their hydrophobic core.

ApoB is an extremely hydrophobic protein, but analysis of the amino acid sequence indicates a lack of membranespanning sequences (Knott et al, 1986) at the difference of membrane proteins. However, it has been shown that apoB is cotranslationally bound to the ER membrane exposing a substantial portion of the molecule to the cytoplasmic side (Chuck and Lingappa, 1992; Boren et al, 1993), thus suggesting that apo $B$ might require a novel translocation process. Thus, Chuck and Lingappa $(1992,1993)$ identified two distinct sequences in apoB (residues 86-99 and 305-318) which appeared to transiently 'pause' the translocation of apoB and stalled apoB in the translocation pore of the ER membrane. Then, the translocation should subsequently restart. The delay that occurs during the translocation process allows lipids to be added to the lipid-binding domains after their shuttle from the ER membranes to the growing apoB peptides in the lumen of the ER via MTP activity. The apoB molecules can, then, fold into a thermodynamically stable conformation before additional sequences are translocated into the lumen of the ER. The relationship between the translation/translocation process of apoB and the production of lipoproteins has been investigated in a series of pulse-chase experiments (Boren et al, 1992). Clearly, nascent polypeptides of apoB, of which molecular weight reached $80-200 \mathrm{kDa}$, were associated with a unique type of lipoprotein. The size of the nascent polypeptides determined the size and the lipid load of the lipoprotein particles. It has recently been shown that nascent lipoproteins in the RER of rat livers already contain sufficient lipids to have diameters in the range of those of native VLDL. These results demonstrate clearly that the formation of apoB-lipoprotein is coupled not only to the translocation of the protein, but also to the translation of this molecule (Dixon and Ginsberg, 1993; Russiñol et al, 1993; Cartwright and Higgins, 1995a).

\section{METABOLIC DEVIATIONS}

Disorders in lipoprotein metabolism can result from abnormal synthesis, processing or catabolism of plasma lipoprotein particles. Abnormal hepatic synthesis of VLDL can lead to hyper- or hyposecretion of these TG-rich lipoproteins in humans and in other mammals, especially farm animals.

\section{VLDL hypersecretion}

Hypersecretion of VLDL is associated with an increased risk of cardiovascular diseases in primates (Alaupovic et al, 1990). These metabolic deviations are generally observed in humans with hormonal (noninsulin-dependent diabetes) or nutritional (obesity) disorders. However, the causes of VLDL hypersecretion have not actually been identified.

\section{Noninsulin-dependent diabetes}

Overproduction of hepatic VLDL particles is frequently observed in humans with a noninsulin-dependent form of diabetes characterized by tissue resistance to insulin. 
This metabolic deviation is not correlated with a hypersynthesis of apoB since the VLDL particles generally exhibit abnormal size and altered chemical composition. Several metabolic abnormalities associated with a noninsulin-dependent form of diabetes, such as hyperglycemia, high plasma level of NEFA and hypoglucagonemia, are each associated with increased hepatic VLDL secretion (Howard, 1987).

\section{Obesity}

Obesity is also associated with the hypersecretion of VLDL by the liver. In this metabolic disease, apoB and TAG secretions both increase to the same extent, leading to higher production of VLDL particles having unchanged size and chemical composition (Gibbons, 1990). Higher hepatic availability and utilization of NEFA for the synthesis of VLDL lipids (Egusa et al, 1985) and insulin resistance frequently observed in obesity can partly explain the hepatic hypersecretion of VLDL observed in obese patients.

\section{$V L D L$ hyposecretion}

Hyposecretion of VLDL in the liver results from the abnormal synthesis of lipoprotein particles. Epidemiologic studies have shown that patients with such disease have, on average, a lower risk for atherosclerotic cardiovascular disease but a higher risk for a variety of cancer, pulmonary or gastrointestinal diseases (Schonfeld, 1995). Fatty liver arises when an imbalance exists between the hepatic TAG formation and the synthesis and/or secretion of VLDL. This imbalance results from alterations in metabolic mechanisms (table I) generally caused by genetic, hormonal or nutritional factors.

\section{Genetic diseases}

VLDL hyposecretion may result from different genetic disorders that lead to hypobetalipoproteinemia (Schonfeld, 1995). Mutations in the apoB gene that impede apoB synthesis or generate several nonfunctional truncated apoB molecules, and mutations in the gene of the large subunit of MTP (Sharp et al, 1993) that lead to an abnormal protein, have been observed in several cases of abetalipoproteinemia in humans (Zannis, 1989; Schonfeld, 1995).

\section{Insulin-dependent diabetes}

Insulin-dependent diabetes reduces VLDL output by stimulating the degradation of newly synthesized apoB by insulin (Van Steenbergen and Lansckmans, 1995). Among other nutritional factors that also reduce VLDL secretion, fish oils (rich in $n-3$ PUFA) increased peroxisomal FA oxidation in hepatocytes, altering the availability of LCFA for TAG synthesis and secretion (Rustan et al, 1992).

\section{Alcohol and liver steatosis (fig 2a)}

The excessive consumption of ethanol is frequently accompanied by malnutrition. Consequently, such dietary habits limit FA absorption but favor a higher mobilization of FA from adipose tissues which are then taken up by the liver. Excess ethanol impairs the mitochondrial oxidation of LCFA, leading to a higher amount of LCFA available for esterification into TAG. When the uptake of exogenous LCFA by the liver exceeds the ability of the liver to assemble and/or secrete the VLDL particles, a fatty liver can then develop (Baraona and Lieber, 1979). Excessive ethanol consumption also causes numerous injuries to the hepatocytes which may impair their protein synthesis, thereby interfering with the availability of apoB. At the subcelluiar level, ethanol can affect one 
Table I. Possible mechanisms involved in the development of liver steatosis.

i. Increased supply of LCFA to the liver resulting from:

- higher LCFA mobilization from adipose tissue

- higher LCFA synthesis in the liver

- lower LCFA oxidation in the liver

ii. Impaired TAG incorporation into VLDL:

- through inhibition of apoB or MTP synthesis

- through production of an inadequate supply of apoB or MTP molecules

- through higher intracellular degradation of apoB

- through competition with $\mathrm{CE}$

iii. Defects in one or several steps in VLDL transport and secretion

- through alterations of VLDL transport from ER to Golgi complex

- through impairment of final apoB glycosylation in Golgi apparatus

- through lower rate of secretory vesicles formation

- through impaired migration of secretory vesicles from Golgi apparatus to cell membranes

Abbreviations given on title page.

or several steps in intracellular transport, packaging or secretion of VLDL particles. These include defects in the movement of VLDL out of the Golgi apparatus associated with an interference between the ethanol and microtubule formation (Baraona and Lieber, 1979). Alcoholic liver disease may be prevented by the supply of adequate nutrients (Derr and Gutmann, 1994). A study in the rat reported that, during prolonged alcohol consumption by rats, a high level of unsaturated fats and low energy in the diet favored fatty liver formation whereas higher energy intake reduced lipid infiltration (Sankaran et al, 1994).

\section{Parenteral nutrition and steatosis (fig 2b)}

Fatty liver is a common abnormality in patients given total parenteral nutrition (Fisher, 1989). Development of the syndrome appears to depend on the amount of glucose infused. Plasma infusion of glucose leads to hyperinsulinemia, which inhibits VLDL secretion. Among the possible explanations is that the accumulation of TAG in the hepatocytes may result from higher peripheral lipolysis, lower LCFA oxidation, higher de novo LCFA synthesis and esterification to TAG, and also higher apoB degradation which impairs the VLDL production. Total parenteral nutrition may provide excess calories with glucose, associated with an inadequate protein or amino acid supply. The addition of a lipid emulsion to parenteral nutrition lowers the portal insulinemia and the portal molar ratio of insulin to glucagon, leading to a reduction in lipid infiltration into the rat liver (Nussbaum et al, 1992). Moreover, it was shown that hepatic steatosis in patients receiving long-term parenteral nutrition was induced by a plasmafree choline deficiency and was reversed using lecithin supplementation (Buchman et al, 1992). 


\section{Poultry and steatosis (fig 2c)}

Fatty liver disease in laying hens is associated with an hemorrhagic syndrome that is induced by a definitive failure of liver reticulin integrity (Hansen and Walzem, 1993). During egg production, high levels of plasma estrogen induce an increased food intake and a state of positive energy balance in the hen. Such metabolic situations favor synthesis of LCFA, TAG and apoproteins in the liver (Dashti et al, 1983). A majority of the neosynthesized TAG, however, is stored in a cytoplasmic pool and probably needs to be hydrolyzed and reesterified into TAG before being incorporated into VLDL particles (Mooney and Lane, 1981). This hydrolysis of TAG is stimulated by food deprivation. The typical ingestive behavior of hens, however, results in a nearly constant fed state. This constant fed state can limit the transfer of TAG from the cytoplasmic stor-
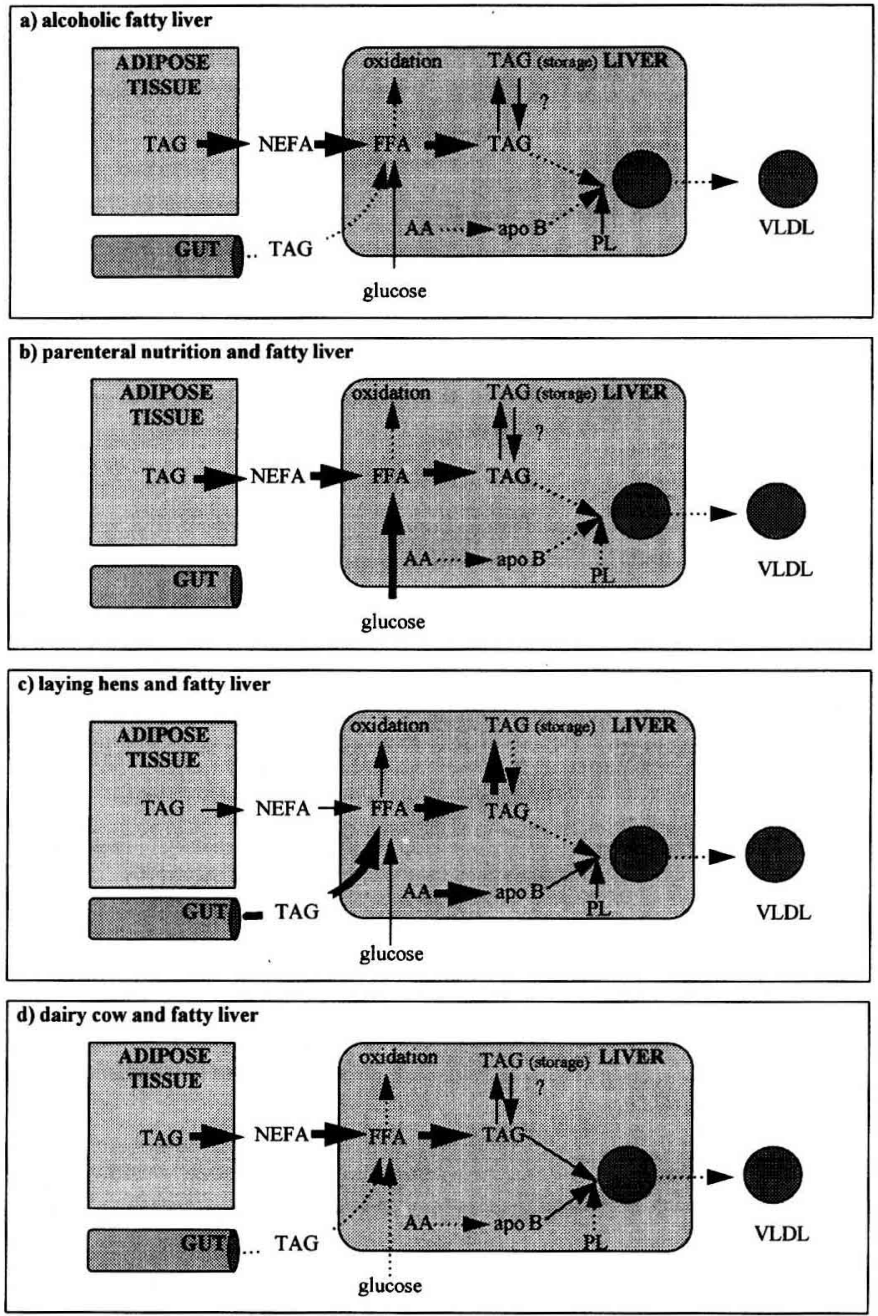

Fig 2. Schematic representation of the metabolic pathways involved in fatty liver development in humans and animals: a) alcoholic fatty liver; b) parenteral nutrition and fatty liver; c) fatty liver in laying hens; d) fatty liver in dairy cows. The large arrow $(\rightarrow)$ indicates the metabolic pathway that is activated and the dotted arrows $(--\rightarrow)$ represent the metabolic pathway that is deactivated. AA: amino acids; apo B: apolipoprotein B; FFA: free fatty acids; NEFA: nonesterified fatty acids; PL: phospholipids; TAG: triacylglycerols; VLDL: very low density lipoproteins. 
age pool to the secretory microsomal pool and their subsequent incorporation in VLDL particles. The chronic and positive energy balance observed in laying hens maintains a relatively high insulinemia (Simon, 1989) which favors the inhibition of VLDL secretion (Simon, 1989). Geese that have been forcefed for 2 weeks with a carbohydrate-rich diet develop dramatic liver steatosis leading to a large increase in liver weight (tenfold). The induction of noteworthy fatty liver is partly under genetic control but the mechanisms of steatosis development are still poorly understood (Hermier et al, 1991). Force-feeding favors hepatic lipogenesis in the goose and produces higher plasma levels of VLDL. These particles, however, are especially enriched in $\mathrm{CE}$, indicating either a defect in the incorporation of TAG into nascent hepatic VLDL particles or a competition between hydrophobic lipids during VLDL packaging (Hermier et al, 1991). Alterations in hepatic secretion of TAG would therefore stimulate liver steatosis.

\section{High producing dairy cows and steatosis (fig 2d)}

Fatty liver is generally seen as a peripartum metabolic disorder that affects one-third of periparturient, high-producing dairy cows (Grummer, 1993). Maximal TAG infiltration occurs between 2 and 4 weeks postcalving $(80-100 \mathrm{mg} / \mathrm{g}$ fresh liver vs $2 \mathrm{mg} / \mathrm{g}$ fresh liver in dry cow) and is the result of excessive FA mobilization when the energy intake is insufficient to support both maintenance and milk production. It disappears after 12 weeks when positive energy balance is restored (Grummer, 1993; Durand et al, 1994).

Another major factor contributing to the development of fatty liver is the chronic slow output of hepatic TAG, which form part of the VLDL particles (Durand et al, 1992; Bauchart, 1993; Grummer, 1993). In early lactation, a decrease in plasma apoB con- centration is correlated with an increase in liver TAG content (Marcos et al, 1990). Similar induction of fatty liver was obtained when ethionine (an inhibitor of protein synthesis) was given to cows, suggesting that apolipoprotein synthesis is a limiting step for VLDL secretion (Uchida et al, 1992). Simultaneous determinations of hepatic levels of apoB, apoB mRNA and TAG clearly showed a negative correlation between apoB gene expression and fatty liver development in the first week of lactation (Gruffat et al, 1994). In other respects, the impairment of the signal transduction pathway mediated by protein kinase $\mathrm{C}$ appears also to be involved in the pathogenesis of fatty liver in cows (Katoh, 1994). Different results suggest a hepatic deficiency in amino acids and in phospholipid precursors in high producing dairy cows in early lactation. Nutritional treatments such as intravenous infusions of L-methionine and L-lysine (Durand et al, 1992) or choline (Juslin et al, 1965), as precursors for $P C$ synthesis, to cows in early lactation favored hepatic VLDL secretion and reduced lipid infiltration. Extensive hydrogenation of dietary PUFA by the rumen bacteria is probably a positive factor that contributes to limiting the extension of hepatic steatosis in dairy cows. Thus, substitution of soybean oil (rich in n-6 PUFA) for tallow rich in saturated and monounsaturated FA in milk replacers for preruminant calves (functional monogastric animals) favored, as in force-feeding goose (Hermier et al, 1991), the hepatic secretion of VLDL enriched in CE to the detriment of TAG which accumulated in the liver (LeplaixCharlat et al, 1996a, b).

\section{CONCLUSION}

This paper reviews data and new concepts on the complex processes involved in VLDL synthesis and secretion in the liver. While the major components of VLDL and their 
pathways synthesis are broadly understood, many aspects of the molecular and cellular mechanisms involved in the assembly and secretion of VLDL particles and their regulation factors need further clarifications. For example, the mechanisms that regulate i) TAG transfer from the cytosolic storage pool to the microsomes; ii) hepatic catabolism of newly synthesized apoB catabolism (involving activity of proteolytic factors); iii) packaging of VLDL components require further investigations to propose adapted treatments against disorders resulting from hepatic over- or hyposecretion of VLDL. Thus, nutritional treatments capable of reducing the development of steatosis, such as balancing the dietary amino acids and dietary long-chain fatty acids and phospholipid precursors, should be examined more thoroughly. These are only a few of the many important questions that need further investigation.

\section{REFERENCES}

Adeli K (1994) Regulated intracellular degradation of apolipoprotein B in semipermeable HepG2 cells. J Biol Chem 269, 9166-9175

Adeli K, Mohammadi A, Macri J (1995) Regulation of apolipoprotein B biogenesis in human hepatocytes: posttranscriptional control mechanisms that determine the hepatic production of apolipoprotein $\mathrm{B}$-containing lipoproteins. Clin Biochem 28, 123-130

Alaupovic P, Blackenhorn DH, Knight-Gibson C, Tavella M, Bard JM, Shafer D, Lee ET, Brasuell J (1990) Apo B-containing lipoprotein particles: a risk factor for coronary artery disease. In: Hypercholesterolemia, Hypocholesterolemia, Hypertriglyceridemia (CL Malmedier et al, eds), Plenum Press, New York, 239-309

AL-Shurbajï A, Larsson-Backström C, Berglund L, Eggersten G, Björkhem I (1991) Effect of $n-3$ fatty acids on the key enzymes involved in cholesterol and triglyceride turnover in rat liver. Lipids 26, 385-389

Atzel A, Wetterau JR (1994) Identification of two classes of lipid molecule binding sites on the microsomal triglyceride transfer protein. Biochemistry $33,15382-$ 15388

Baraona E, Lieber CS (1979) Effects of ethanol on lipid metabolism. J Lipid Res 20, 289-315
Bauchart D (1993) Lipid absorption and transport in ruminants. J Dairy Sci 76, 3864-3881

Bennett AJ, Billett MA, Salter AM, White DA (1995) Regulation of hamster hepatic triglyceride transfer protein mRNA levels by dietary fats. Biochem Biophys Res Commun 212, 473-478

Borchardt R, Davis R (1987) Intrahepatic assembly of very-low density lipoproteins. J Biol Chem 262, 16394-16402

Boren J, Graham L, Wettesten M, Scott J, White A, Olofsson S (1992) The assembly and secretion of apoB100 -containing lipoproteins in HepG2 cells. J Biol Chem 267, 9858-9867

Boren J, Wettesten M, Rustaeus S, Andersson M, Olofsson $S$ (1993) The assembly and secretion of apoB100-containing lipoproteins. Biochem Soc Trans 21 , 487-493

Buchman AL, Dubin $M_{1}$ Jenden D, Moukarzl A, Roch $\mathrm{MH}$, Rice K, Gorbein J, Ament ME, Eckhert CD (1992) Lecithin increases plasma free choline and decreases hepatic steatosis in long-term parenteral nutrition patients. Gastroenterology 102, 1363-1370

Cartwrighı IJ, Higgins JA (1995a) The role of intracellular proteolysis in the regulation of apoliprotein $B$ secretion by rabbit hepatocytes. Biochem Soc Trans 23, $413 \mathrm{~S}$ (abstr)

Cartwright IJ, Higgins JA (1995b) Intracellular events in the assembly of very-low-density-lipoprotein lipids with apolipoprotein $B$ in isolated rabbit hepatocytes. Biochem J 310, 897-907

Chuck SL, Lingappa VR (1992) Pause transfer: a topogenic sequence in apolipoprotein $B$ mediates stopping and restarting of translocation. Cell $68,9-21$

Chuck SL, Lingappa VR (1993) Analysis of a pause transfer sequence from apolipoprotein B. J Biol Chem 268, 22794-22801

Cianflone K, Yasruel Z, Rodriguez M, Vas D, Sniderman A (1990) Regulation of apoB secretion from HepG2 cells: evidence for a critical role for cholesteryl ester synthesis in the response to a fatty acid challenge. J Lipid Res 31, 2045-2055

Dashti $N$ (1992) The effect of low-density lipoproteins, cholesterol, and 25 $\alpha$-hydroxycholesterol on apolipoprotein B gene expression in HepG2 cells. $J$ Biol Chem 267, 7169-7180

Dashti N, Kelley JL, Thayer RH, Ontko JA (1983) Concurrent inductions of avian hepatic lipogenesis, plasma lipids, and plasma apolipoprotein B by estrogen. J Lipid Res 24, 368-380

Dashti N, Williams D, Alaupovic P (1989) Effects of oleate and insulin on the production rates and cellular mRNA concentrations of apolipoproteins in HepG2 cells. J Lipid Res $30,1365-1373$

Derr RF, Gutmann HR (1994) Alcoholic liver disease may be prevented with adequate nutrients. Med Hypotheses 42, 1-4 
Dixon JL, Ginsberg HN (1993) Regulation of hepatic secretion of apolipoprotein B-containing lipoproteins: information obtained from cultured liver cells. $J$ Lipid Res 34, 167-179

Dixon JL, Furukawa S, Ginsberg HN (1991) Oleate stimulates secretion of apolipoprotein B-containing lipoproteins from HepG2 cells by inhibiting early intracellular degradation of apolipoprotein B. J Biol Chem 266, 5080-5086

Durand D, Chilliard Y, Bauchart D (1992) Effects of lysine and methionine on in vivo hepatic secretion of VLDL in high yielding dairy cow. J Dairy Sci 75, 279 (Abstr)

Durand D, Martinaud M, Gruffat D, Leplaix L, Lefaivre J, Ollier A, Robert JC, Chilliard Y, Bauchart D (1994) Plasma and hepatic lipids and lipoproteins in the underfed high-yielding dairy cow during early lactation. Ann Zootech 43, 46S

Egusa G, Beitz WF, Grundy SM, Howard BV (1985) Influence of obesity on the metabolism of apolipoprotein B in humans. J Clin Invest 76, 596-603

Fisher RL (1989) Hepatobiliary abnormalities associated with total parenteral nutrition. Gastroenterol Clin North Am 18, 645-666

Francone OL, Griffaton G, Kalopissis AD (1992) Effect of high-fat diet on the incorporation of stored triacylglycerol into hepatic VLDL. Am J Physiol 263, E615. E623

Furukawa S, Sakata N, Ginsberg HN, Dixon JL (1992) Studies of the sites of intracellular degradation of apolipoprotein B in HepG2 cells. J Biol Chem 267 , 22630-22638

Geelen MJH, Schoots WJ, Bijleveld C, Beynen AC (1995) Dietary medium-chain fatty acid raise and (n3) polyunsaturated fatty acids lower hepatic triacylglycerol synthesis in rats. J Nutr 125, 2449-2456

Gibbons GF (1990) Assembly and secretion of hepatic very-low-density lipoprotein. Biochem J 268, 1-13

Gibbons GF, Bartlett SM, Sparks CE, Sparks JD (1992) Extracellular fatty acids are not utilized directly for the synthesis of very-low-density lipoproteins in primary cultures of rat hepatocytes. Biochem $J 287$, 749-753

Glickman RM, Sabesin SM (1994) Lipoprotein metabolism. In: The Liver: Biology and Pathology, 3rd edn (IM Arias, JL Boyer, N Fausto, WB Jakoby, DA Schachter, DA Shafritz, eds), Raven Press, New York, 391-414

Gordon DA, Wetterau JR, Gregg RE (1995) Microsomal triglyceride transfer protein: a protein complex required for the assembly of lipoprotein particles. Trends Cell Biol 5, 317-321

Gruffat D, Duboisset F, Durand D, Lefaivre J, Ollier A, D'Onofrio G, Williams P, Chilliard $Y$, Bauchart D (1994) Hepatic apo $B$ and mRNA apo $B$ levels in the underfed high-producing dairy cows during early lactation. Ann Zootech 43, 48 S (abstr)
Grummer RR (1993) Ethiology of lipid-related metabolic disorders in the periparturient dairy cows. J Dairy Sci 76, 3882-3896

Halminski MA, Marsh JB, Harrisson EH (1991) Differential effects of fish oil, safflower oil and palm oil on fatty acid oxidation and glycerolipid synthesis in rat liver. J Nutr 121, 1554-1561

Hansen RJ, Walzem RL (1993) Avian fatty liver hemorrhagic syndrome: a comparative review. Adv $\mathrm{Vet} S \mathrm{SC}$ Comp Med 37, 451-468

Hellerstein HK, Christiansen M, Kaempfer S, Kletke C, Wu K, Reid JS, Mulligan K, Hellerstein MS, Shackleton $\mathrm{CHL}$ (1991) Measurement of de novo hepatic lipogenesis in humans using stable isotopes. $J$ Clin Invest $87,1841-1852$

Hermier D, Saadoun A, Salichon MS, Rousselot-Paillet D, Chapman MJ (1991) Plasma lipoproteins and liver lipids in two breeds of geese with different susceptibility to hepatic steatosis: changes induced by development and force-feeding. Lipids 26, 331-339

Howard BV (1987) Lipoprotein metabolism in diabetes mellitus. $J$ Lipid Res 28, 613-627

Jamil H, Dickson JK, Chu CH, Lago MW, Rinehart JK, Biller SA, Gregg RE, Wetterau JR (1995) Microsomal triglyceride transfer protein, specificity of lipid binding and transport. J Biol Chem 270, 6549-6554

Juslin KE (1965) On the effect of choline chloride on cyanocobalamine on the livers of cows with parturient paresis. North Vet 17, 169-175

Kaptein A, Roodenburg L, Princen H (1991) Butyrate stimulates the secretion of apolipoprotein (apo) A-I and apo B-100 by the human hepatoma cell line HepG2. Biochem J 278, 557-564

Katoh N (1994) Reduced protein kinase $C$ activity and endogeneous protein phosphorylation in ethionineinduced fatty liver in cows. Vet Res Commun 18 , 423-432

Knott TJ, Pease RJ, Powell LM, Wallis SC, Rall SC, Innerarity $T L$, Blackhart $B$, Taylor $W H$, Marcel $Y$, Milne R, Johnson D, Fuller M, Lusis AJ, McCarthy BJ, Mahley RW, Levy-Wilson B, Scott J (1986) Complete protein sequence and identification of structural domains of human apolipoprotein B. Nature 323, 734-738

Leplaix-Charlat L, Bauchart D, Durand D, Laplaud PM, Chapman MJ (1996a) Plasma lipoproteins in preruminant calves fed diets containing tallow or soybean oil with or without cholesterol. J Dairy Sci 79 (in press)

Leplaix-Charlat L, Bauchart D, Durand D (1996b) Effects of tallows- and soybean oil-containing diets with or without cholesterol on hepatic metabolism of lipids and lipoproteins in the preruminant calf, Boss spp. $\checkmark$ Dairy Sci 79 (in press)

Lin MCM, Arbeeny C, Bergquist K, Kienzle B, Gordon DA, Wetterau JR (1994) Cloning and regulation of 
hamster microsomal triglyceride transfer protein. $\checkmark$ Biol Chem 268, 29138-29145

Lin MCM, Gordon D, Wetterau JR (1995) Microsomal triglyceride transfer protein (MTP) regulation in HepG2 cells: insulin negatively regulates MTP gene expression. J Lipid Res 36, 1073-1081

McGarry JD, Foster DW (1980) Regulation of hepatic fatty acid oxidation and ketone body concentrations. Annu Rev Biochem 49, 395-420

McGarry JD, Stark MJ, Foster DW (1978) Hepatic malonyl-CoA levels of fed, fasted and diabetic rats as measured using a simple radioisotopic assay. J Biol Chem 253, 8291-8293

Marcos E, Mazur A, Cardot P, Rayssiguier Y (1990) The effect of pregnancy and lactation on serum lipid and apolipoprotein B and A-I levels in dairy cows. J Anim Physiol Anim Nutr 64, 133-138

Mooney RA, Lane MD (1981) Formation and turnover of triglyceride-rich vesicles in the chick liver cell. J Biol Chem 256, 11724-11733

Nussbaum MS, Li S, Bower RH, McFadden DW, Dayal R, Fischer JE (1992) Addition of lipid to total parenteral nutrition prevents hepatic steatosis in rats by lowering the portal venous insulin/glucagon ratio. $J$ Parenter Nutr 16, 106-109

Pethick DW, Bell AW, Annison EF (1984) Fats as energy sources in animal tissues. In: Fats and Animal Nutrition (J Wiseman, ed), Butterworths, London, UK, 225-248

Pullen DL, Emery RS, Ames NK (1988) Turnover of hepatic and plasma triacylglycerol in sheep. J Anim Sci $66,1538-1547$

Pullinger C, North J, Teng B, Rifici VA, Ronhild de Brito $A E$, Scott $J(1989)$ The apolipoprotein $B$ gene is constitutively expressed in HepG2 cells: regulation of secretion by oleic acid, albumin, and insulin, and measurement of the mRNA half-life. J Lipid Res 30 , 1065-1077

Robinson BS, Yao Z, Baisted DJ, Vance DE (1989) Lysophosphatidylcholine metabolism and lipoprotein secretion by cultured rat hepatocytes deficient in choline. Biochem J 260, 207-214

Rule DC (1994) Effects of dietary fatty acid composition on glycerophosphate acyltransferase activity in rat adipose tissue and liver. Int J Biochem 26, 49-54

Russiñol AE, Chan EY, Vance JE (1993) Movement of apolipoprotein $B$ into the lumen of microsomes from hepatocytes is disrupted in membranes enriched in phosphatidyl-monoethanolamine. J Biol Chem 268, 25168-25175

Rustan AC, Christiansen EN, Drevon CA (1992) Serum lipids, glycerolipid metabolism and peroxisomal fatty acid oxidation in rats fed $\omega-3$ and $\omega-6$ fatty acids. Biochem J 283, 333-339

Sakata N, Wu X, Dixon JL, Ginsberg HN (1993) Proteolysis and lipid-facilitated translocation are distinct but competitive processes that regulate secretion of apolipoprotein B in HepG2 cells. J Biol Chem 268 , 22967-22970

Sankaran H, Larwin EC, Rao GA (1994) Unsaturated fat and low energy intake induce whereas an increment in energy intake ameliorates fatty liver during prolonged alcohol consumption by rats. J Nutr 124 , 110-116

Sato R, Imanaka T, Takasuki A, Takano A (1990) Degradation of newly synthetized apoliprotein B-100 in the pre-Golgi compartment. J Biol Chem 265, 1188011884

Schonfeld G (1995) The hypobetalipoproteinemias. Annu Rev Nutr 15, 23-34

Sharp D, Blinderman L, Combs KA, Kienzle B, Ricci B, Wager-Smith K, Gil CM, Turk CW, Bouma ME, Rader DJ, Aggerbeck LP, Gregg RE, Gordon DA, Wetterau JR (1993) Cloning and gene defect in microsomal triglyceride transfer protein associated with abetalipoproteinemia. Nature $365,65-68$

Simon J (1989) Chicken as a useful species for the comprehension of insulin action. CRC Crit Rev Poultry Biol 2, 121-148

Sparks J, : iparks C (1990) Insulin modulation of hepatic synthesis and secretion of apolipoprotein $B$ by rat hepatocytes. J Biol Chem 265, 8854-8862

Stals HK, Top W, Declercq PE (1994) Regulation of triacylglycerol synthesis in permeabilized rat hepatocytes. FEBS Lett 343, 99-102

Theriault A, Ogbonna G, Adeli K (1992a) Thyroid hormone modulates apolipoprotein $B$ gene expression in HepG2 cells. Biochem Biophys Res Commun 186, 617-623

Theriault A, Tcheung R, Adeli K (1992b) Expression of apoliprotein $B$ in vitro in cell-free lysate of HepG2 cells: evidence that insulin modulates apo B synthesis at the translational level. Clin Biochem 25, 321-323

Uchida E, Katoh N, Takahashi K (1992) Induction of fatty liver in cows by ethionine administration and concomitant decreases of serum apolipoprotein B100 and A-I concentrations. Am J Vet Res 53, 20352042

Vance JE, Vance DE (1990) Lipoprotein assembly and secretion by hepatocytes. Annu Rev Nutr 10, $337-$ 356

Vancura A, Haldar D (1992) Regulation of mitochondrial and microsomal phospholipid synthesis by liver fatty acid binding protein. J Biol Chem 267, 1435314359

Vancura A, Haldar D (1994) Purification and characterization of glycerophosphate acyltransferase from rat liver mitochondria. J Biol Chem 269, 27209-27215

Van Steenbergen W, Lanckmans S (1995) Liver disturbances in obesity and diabetes mellitus. Int $J$ Obesity 19, S27-S36 
Verkade HJ, Fast DG, Rusinol AE, Scraba DG, Vance DE (1993) Impaired synthesis of phosphatidylcholine causes a decrease in the number of very-low density lipoprotein particles in the Golgi but not in the endoplasmic reticulum of rat liver. J Biol Chem 268, 24990-24996

Wetterau JR, Combs KA, McLean LR, Spinner SN Aggerbeck LP (1991) Protein disulfide isomerase appears necessary to maintain the catalytically active structure of the microsomal triglyceride transfer protein. Biochemistry 30, 9728-9735

White AL, Graham DL, LeGros J, Pease RJ, Scott J (1992) Oleate-mediated stimulation of apolipoprotein B secretion from rat hepatoma cells. $J$ Biol Chem $267,15657-15664$

Wiggins D, Gibbons GF (1992) The lipolysis/esterification cycle of hepatic triacylglycerol. Biochem $J 284$, 457-462

Willumsen N, Shorve J, Hexeberg S, Rustan AC, Berge RK (1993) The hypotriglyceridemia effect of eicosapentanoic acid in rats is reflected in increased mitochondrial fatty acid oxidation followed by diminished lipogenesis. Lipids 28,683-690
Wu X, Sakata N, Dixon J, Ginsberg HN (1994) Exogeneous VLDL stimulates apolipoprotein B secretion from HepG2 cells by both pre- and post-translational mechanisms. J Lipid Res 35, 1200-1210

Yao Z, Vance DE (1988) The active synthesis of phosphatidylcholine is required for very-low density lipoprotein secretion from rat hepatocytes. $J$ Biol Chem 263, 2998-3004

Yao Z, Vance DE (1989) Head group specificity in the requirement of phosphatidylcholine biosynthesis for very-low density lipoprotein secretion from cultured hepatocytes. I Biol Chem 264, 11373-11380

Young SG (1990) Recent progress in understanding apolipoprotein B. Circulation 82, 1574-1594

Zammit VA (1990) Ketogenesis in the liver of ruminants - adaptations to a challenge. J Agric Sci 115, 155162

Zammit VA (1995) Insulin and the partitioning of hepatic fatty acid metabolism. Biochem Soc Trans 23 . 506-511

Zannis VI (1989) Molecular biology of human apolipoproteins $B$ and $E$ and associated diseases of lipoprotein metabolism. Adv Lipid Res 23, 1-64 